\title{
ABORDAGEM FONOAUDIOLÓGICA EM DESVIOS FONOLÓGICOS FUNDAMENTADA NA HIERARQUIA DOS TRAÇOS DISTINTIVOS E NA CONSCIÊNCIA FONOLÓGICA
}

\author{
Phonological awareness and hierarchy of distinctive features \\ determine speech therapy for phonological deviations
}

\author{
Rafaela de Almeida Spíndola ${ }^{(1)}$, Luzia Miscow da Cruz Payão ${ }^{(2)}$, Heloísa Helena Motta Bandini ${ }^{(3)}$
}

\begin{abstract}
RESUMO
Objetivo: verificar a evolução do sistema fonológico alvo-adulto de crianças com desvio fonológico na faixa etária de 05 a 08 anos, estudantes de escola pública. Métodos: a partir da análise de gravações em áudio digital de amostra de fala espontânea, nomeação de gravuras e imitação de vocábulos que compõem um teste fonológico específico (ABFW), identificou-se os processos fonológicos atuantes. Foi aplicado um programa de atividades estimulando as habilidades de consciência fonológica, tendo como base teórica da hierarquia dos traços distintivos. Resultados: todos os pacientes apresentaram evolução significativa após o término do programa, superando todos os processos fonológicos presentes e adquirindo os traços que estavam ausentes. Os pacientes ampliaram seu sistema fonológico à medida que melhoraram seu desempenho nas atividades de consciência fonológica. Conclusão: a abordagem fonoaudiológica de desvio fonológico baseada na hierarquia dos traços distintivos e na consciência fonológica favoreceu a superação de processos fonológicos e a evolução significativa do sistema fonológico dos pacientes.
\end{abstract}

DESCRITORES: Fonoterapia; Fonética; Fala; Linguagem

\section{INTRODUÇÃO}

O desvio fonológico é caracterizado por alterações que ocorrem na fala da criança, em que esta realizará uma produção inadequada dos fonemas, bem como o uso inadequado das regras fonológicas da língua ${ }^{1}$. Esse transtorno lingüístico é representado por crianças as quais apresentam alterações na produção da fala, na ausência de determinados fatores etiológicos como: dificuldade geral de aprendizagem, déficit intelectual, desordem neuromotora, distúrbios psiquátricos, problemas otológicos ou fatores ambientais ${ }^{2}$.

(1) Aluna do curso de Fonoaudiologia da Universidade Estadual de Ciências da Saúde de Alagoas.

(2) Fonoaudióloga; Professora assistente da disciplina Abordagem Terapêutica em Linguagem e supervisora do Estágio Supervisionado em Linguagem da Universidade Estadual de Ciências da Saúde de Alagoas; Mestre em Lingüística pela Universidade Federal de Alagoas.

(3) Fonoaudióloga; Professora auxiliar da disciplina de Audiologia Educacional e de Aparelhos de Amplificação Sonora Individual da Universidade Estadual de Ciências da Saúde de Alagoas; Doutora em Educação Especial pela Universidade Federal de São Carlos.
A aquisição fonológica normal é caracterizada por produções governadas por processos fonológicos considerados simplificações realizadas pela criança, visando facilitar aspectos complexos da fala dos adultos. Esses processos estão presentes nas primeiras fases do desenvolvimento lingüístico. À medida que a criança vai aprendendo sua língua, esses processos devem ser superados, permitindo a adequação para o padrão adulto. Quando os processos fonológicos naturais não são suprimidos até os 4 anos de idade, essas crianças são classificadas como portadoras de desvio fonológico ${ }^{3}$.

A aquisição fonológica de um sistema lingüístico é estabelecida gradualmente a partir da operação mental realizada entre unidades menores que os fonemas, ou seja, os traços distintivos. Estes são unidades mínimas de caráter acústico ou articulatório que entram na composição de um som ${ }^{4}$. Os traços proporcionam a relação entre a representação cognitiva da fala e a manifestação física e obedecem às leis implicacionais que regem a teoria da hierarquia dos traços distintivos. Dessa forma, podem prever a ordem de aquisição dos contrastes fonológicos 
pela criança, adquirindo inicialmente os traços básicos antes dos mais complexos ${ }^{5}$.

Esses princípios da hierarquia dos traços distintivos podem ser bastante produtivos no planejamento e aplicação de uma terapia fonoaudiológica, considerando o processo de generalização e rapidez no estabelecimento dos padrões fonológicos ${ }^{6}$. O processo de generalização é a ampliação da produção adequada de sons-alvo trabalhados em terapia para outros conteúdos que ainda não foram estimulados, devido à consciência fonológica que se desenvolve ${ }^{7}$.

A consciência fonológica caracteriza-se pela representação mental das menores unidades constituintes da fala, ou seja, os sons que compõem as palavras $^{8}$. A partir da consciência fonológica o indivíduo reconhece que as palavras são formadas por diferentes sons que podem ser manipulados, refletindo a capacidade de operar com fonemas, sílabas, rimas e aliterações ${ }^{9}$.

As habilidades de consciência fonológica podem ser analisadas por três grupos distintos: habilidades suprasegmentares, caracterizadas pelo julgamento de palavras que terminem ou iniciem com o mesmo som; habilidades silábicas, que envolve a segmentação, adição, remoção e troca de sílabas de palavras; habilidades fonêmicas, baseadas em decompor ou recompor palavras manipulando os seus fonemas constituintes ${ }^{10}$.

Assim, a consciência fonológica pode ser vista como uma hierarquia de processos baseados nos níveis de complexidade do sistema fonológico. Um nível mais alto de consciência requer uma análise minuciosa das menores unidades do sistema fonológico, como, por exemplo, os fonemas; e um nível mais rudimentar de consciência requer uma análise mais superficial de unidades maiores de sons, as sílabas ${ }^{11}$.

A descoberta dos segmentos fonêmicos pela criança pode resultar em mudança na maneira como as palavras estão estruturadas cognitivamente. Esse processo pode ser alcançado por meio de treinamento em consciência fonológica ${ }^{12}$. A estruturação de uma proposta terapêutica baseada nesse pressuposto irá facilitar o desenvolvimento do sistema fonológico da criança e, conseqüentemente, propiciar agilidade no processo terapêutico, evitando assim o agravamento do problema.

O estudo a seguir tem como objetivo verificar a evolução do sistema fonológico alvo-adulto de quatro crianças com diagnóstico fonoaudiológico de desvio fonológico, mediante a aplicação de um programa de atividades baseado na hierarquia dos traços distintivos e na consciência fonológica.

\section{MÉTODOS}

Os critérios de inclusão para a escolha dos sujeitos da pesquisa foram: crianças na faixa etária de 5 a 8 anos, com diagnóstico de desvio fonológico, em atendimento fonoaudiológico por pelo menos 2 meses em uma unidade de tratamento em fonoaudiologia do estado de Alagoas. E os critérios de exclusão foram: participante com alteração estrutural significativa dos órgãos fonoarticulatórios; presença de qualquer distúrbio neurológico; constatação de perda auditiva e que, após a coleta de dados, apresentassem mais de $25 \%$ de faltas nas sessões.

Foram selecionadas cinco crianças de acordo com os critérios de inclusão anteriormente referidos. Entretanto, apenas quatro participaram da pesquisa, pois uma delas teve seus dados excluídos do estudo em decorrência do número de faltas exceder os $25 \%$ permitidos.

Foram realizadas as avaliações dos aspectos fonético-fonológicos das crianças individualmente, para análise dos processos fonológicos. Para avaliação foram escolhidas as provas de nomeação e imitação contidas no ABFW ${ }^{13}$ e uma amostra de fala espontânea. Toda a avaliação foi registrada em áudio e analisada posteriormente. O ABFW foi escolhido porque é um teste atualizado que analisa as alterações de fala na perspectiva fonológica, identificando os processos fonológicos e os traços distintivos ausentes ou instáveis no sistema fonológico da criança. Para a transcrição da fala foi utilizado o Alfabeto Fonético Internacional (IPA - International Phonetic Alphabet, 1993) ${ }^{14}$.

Após caracterização do sistema fonológico de cada participante, foi iniciada a aplicação do programa de estratégias de estimulação da consciência fonológica. O programa foi executado no total de 13 sessões, realizadas semanalmente, com duração de 30 minutos cada. Todo o estudo foi conduzido no período de março a julho de 2006.

Inicialmente as sessões foram realizadas individualmente com três dos cinco sujeitos e os outros dois foram unidos em dupla, pois eram irmãos e apresentavam sistemas fonológicos semelhantes. Após a primeira sessão de aplicação do programa, a dupla foi desfeita devido à competitividade expressa pelos irmãos, tornando assim todos os atendimentos individuais.

O programa de estratégias para desenvolver a consciência fonológica (Figura 1) baseou-se em estudos específicos ${ }^{15,16}$, caracterizados pela aplicação de atividades envolvendo as seguintes habilidades de consciência fonológica: aliteração, rima, síntese silábica, segmentação silábica, manipulação silábica, 
transposição silábica, identificação fonêmica, síntese fonêmica, segmentação fonêmica.

Todas as habilidades foram trabalhadas por meio de atividades lúdicas, utilizando palavras-alvo relacionadas com os traços comprometidos.

O programa foi iniciado com a aplicação de atividades lúdicas de rima e aliteração, trabalhadas em 2 sessões conjuntamente, sendo 15 minutos reservados para a primeira habilidade e os outros 15 minutos para a segunda. Procedeu-se da mesma forma para as demais habilidades: síntese e segmentação silábica, manipulação e transposição silábica, síntese e segmentação fonêmica e manipulação e transposição fonêmica. Apenas a atividade de identificação fonêmica foi realizada em duas sessões isoladamente. Entretanto, ao observar o desempenho insatisfatório nas habilidades fonêmicas, as pesquisadoras decidiram interrompê-las e retornar às atividades com as habilidades silábicas, mantendo a mesma quantidade de estratégias aplicadas.

À medida que as atividades do programa foram aplicadas, o desempenho das crianças em cada sessão foi registrado minuciosamente e descrito posteriormente. Após o término do programa, foi realizada nova avaliação do sistema fonológico das crianças, por meio do ABFW, para analisar a evolução fonológica de cada sujeito.

A presente pesquisa foi aprovada pelo Comitê de Ética em Pesquisa (CEP), protocolo número 457, da Universidade Estadual de Ciências da Saúde de Alagoas-UNCISAL.

\section{RESULTADOS}

Evolução do sistema fonológico no decorrer da aplicação do programa (Figura 4)

\section{Sujeito I}

Sujeito I, 8 anos, sexo masculino, estudante da $1^{\text {a }}$ série do ensino fundamental em escola municipal da cidade de Maceió-AL. De acordo com a análise fonológica realizada, o sujeito I apresentava os seguintes processos fonológicos: ensurdecimento de plosivas e fricativas, em que o traço comprometido era o [+voz] $(/ \mathrm{g} / \rightarrow[\mathrm{k}], / \mathrm{b} / \rightarrow[\mathrm{p}],|\mathrm{z} / \rightarrow[\mathrm{s}],| \mathrm{Z} / \rightarrow[\Sigma])$; simplificação de líquidas, com ausência do traço [+contínuo] (/P/ à [I]) e simplificação de encontros consonantais (omissão do fonema /P/ em sílabas CCV-consoante-consoante-vogal).

Os primeiros fonemas a serem trabalhados foram o /Z/ e o /z/, os quais eram trocados pelos fonemas $[\Sigma]$ e [s], respectivamente. Para a estimulação do traço [+voz] foram utilizadas palavras com as fricativas
|Z/ e /z/, por terem a duração maior, facilitando a percepção do traço.

Durante as duas sessões reservadas para as atividades de aliteração e rima, o paciente apresentou dificuldade em produzir os fonemas inseridos na palavra, mesmo com o auxílio da terapeuta, porém, no decorrer da atividade, ele conseguiu inseri-los na palavra, apoiando-se nas pistas fornecidas.

Após a realização das atividades de segmentação e síntese silábica o paciente evoluiu, não necessitando mais de pistas, conseguindo produzir a palavra corretamente após o estranhamento da terapeuta. $\mathrm{O}$ estranhamento constava de um questionamento a respeito da palavra dita inadequadamente pela criança e realização de autocorreções subseqüentes.

Nas atividades de manipulação e transposição silábicas, o paciente conseguiu produzir o fonema /Z/ durante a nomeação das palavras, sem o auxílio de pistas ou estranhamentos. Entretanto, no que se refere ao fonema /z/, somente o inseriu na palavra após o oferecimento das pistas dadas pela terapeuta.

Nas sessões utilizadas para trabalhar a identidade fonêmica, o paciente demonstrou uma evolução bastante significativa quanto ao traço [+voz] nas palavrasalvo utilizadas com fonemas fricativos. A aquisição do traço [+voz] generalizou-se para os fonemas plosivos / $\mathrm{b} / \mathrm{e} / \mathrm{g} /$. Um aspecto importante observado foi o início da produção adequada da vibrante simples / P/, a qual era trocada pela líquida [l], adquirindo assim o traço [+contínuo] que a distingue da vibrante simples /P/da líquida não vibrante.

Nas últimas atividades de segmentação e síntese silábica, foram inseridas palavras-alvos com o fonema $/ \mathrm{P} /$, conseguindo pronunciá-lo adequadamente na maioria das vezes. Em relação aos outros fonemas plosivos e fricativos trabalhados, a criança já consegue produzi-los em fala espontânea.

Para finalização do programa foram realizadas atividades de manipulação e transposição silábica, inserindo a líquida vibrante simples /P/ em encontros consonantais. O paciente conseguiu produzir adequadamente as sílabas CCV nas palavras-alvo.

\section{Sujeito II}

Sujeito II, 7 anos, sexo masculino, estudante da $1^{\text {a }}$ série do ensino fundamental em escola municipal da cidade de Maceió-AL. Foi observada a presença dos seguintes processos fonológicos no sujeito II: ensurdecimento de plosivas e fricativas, havendo ausência do traço $[+\mathrm{voz}](/ \mathrm{g} / \rightarrow[\mathrm{k}], / \mathrm{b} / \rightarrow[\mathrm{p}], / \mathrm{z} / \rightarrow[\mathrm{s}]$, $|Z| \rightarrow[\Sigma]$ ); simplificação de líquidas e simplificação de encontros consonantais, comprometendo, portanto, o traço [+contínuo] (/P/ à [l]). Adotou-se o mesmo 
procedimento realizado com o sujeito I, iniciando o programa com palavras-alvo contendo fricativas.

Nos dois primeiros dias de aplicação do programa (aliteração e rima) o paciente já conseguiu produzir os fonemas fricativos inseridos nas palavras durante nomeação, entretanto, necessitou, algumas vezes, da ajuda de pistas para perceber o traço [+ voz], superando esse processo fonológico.

Durante a aplicação das atividades de segmentação e síntese silábica e posteriormente de manipulação e transposição silábica o paciente apresentou evolução significativa, conseguindo pronunciar todas as palavras adequadamente. Foi observada também a aquisição do traço [+ voz] nos fonemas plosivos /b/ e /g/, realizando assim o processo de generalização.

Nas atividades de identificação fonêmica, o paciente continuou a apresentar evolução, ampliando o sistema fonológico.

Nas últimas atividades realizadas de segmentação e síntese silábica, devido à aquisição do traço [+voz] e superação do processo fonológico de ensurdecimento, foram inseridas palavras contendo o fonema /P/. O paciente estava realizando, inicialmente, uma produção exagerada do fonema, porém conseguiu emiti-lo corretamente, ajustando a produção em palavras-alvo do programa.

Foi dada continuidade ao trabalho em atividades de manipulação e transposição silábica com o fonema /P/ isolado, e também em encontros consonantais. O paciente conseguiu evoluir em relação à produção do fonema /P/, não pronunciando da forma exagerada inicial, superando aqui a dificuldade anteriormente presente no traço [+contínuo] para distinção das líquidas. Generalizou a produção da vibrante simples /P/, em sílaba CV (consoante-vogal) menos complexa e nos encontros consonantais (CCV), numa estrutura silábica mais complexa.

\section{Sujeito III}

Sujeito III, 6 anos, sexo feminino, cursando a alfabetização em escola municipal da cidade de MaceióAL. O sujeito III apresentava os seguintes processos fonológicos: plosivação de fricativas, em que o traço comprometido era [+ contínuo] (/Z/ e /z/ $\rightarrow$ [d]; / $\Sigma /$ e /s/à [t]); frontalização de velares, caracterizada pela ausência do traço [dorsal] $(/ \mathrm{k} /$ à [t] e $/ \mathrm{g} / \rightarrow$ [d]) e simplificação de encontros consonantais, realizando omissão do fonema /P/ na estrutura CCV.

A aplicação das atividades de aliteração e rima visou à superação da plosivação de fricativas. Para isso foram utilizadas palavras contendo os fonemas $/ \Sigma /$ e $/ Z /$, os quais apresentam uma mai- or duração, facilitando a percepção do traço [+contínuo], o qual estava ausente no sistema fonológico da criança. A paciente conseguiu produzir adequadamente os fonemas $/ \Sigma / \mathrm{e} / \mathrm{Z} /$, tanto isoladamente quanto inserido na palavra, necessitando de algumas pistas da terapeuta.

No segundo dia de aplicação, foram inseridos os fonemas /s/ e /z/ devido ao seu bom desempenho com relação aos fonemas trabalhados na sessão anterior. A paciente conseguiu produzi-los isoladamente e inseri-los em palavras-alvo nas atividades do programa e durante a fala espontânea, numa situação de contagem numérica. Apresentou maior dificuldade quando os fonemas encontravam-se em onset medial (início da sílaba mediana da palavra).

Nas sessões de aplicação das atividades de segmentação e síntese silábica de manipulação e transposição silábica, foram inseridos os fonemas $/ \mathrm{k} /$ e $/ \mathrm{g} /$, e a paciente já conseguiu produzi-los adequadamente sem necessidade de pistas e de poucos estranhamentos sinalizados pela terapeuta.

Nas atividades de identificação fonêmica a paciente mostrou uma evolução significativa, observando-se assim a superação dos processos fonológicos de plosivação de fricativas e frontalização de velares, adquirindo, respectivamente, os traços [+ contínuo] e [dorsal].

Durante as atividades de segmentação e síntese silábica, aplicadas novamente, a paciente continuou demonstrando evolução, referindo todas as palavras adequadamente sem apoio da terapeuta. Foi inserido o fonema /R/ na terapia, sendo este falado pela paciente sem nenhuma dificuldade.

Finalizando o programa, foram aplicadas atividades de manipulação e transposição silábica, com o fonema vibrante simples / $/ \mathrm{P}$ em sílaba $\mathrm{CV}$, e também em encontro consonantal, produzindo adequadamente os fonemas, necessitando de pistas da terapeuta em poucos momentos durante a produção dos encontros consonantais CCV.

\section{Sujeito IV}

Sujeito IV, 8 anos, sexo masculino, estudante da $1^{a}$ série do ensino fundamental em escola municipal da cidade de Maceió-AL. O sujeito IV apresentava os seguintes processos fonológicos: plosivação de fricativas, caracterizada pela ausência do traço [+contínuo] (/Z/ e /z/ $\rightarrow$ [d]; /S/ e /s/ $\rightarrow$ [t]) e simplificação de encontros consonantais, omitindo a vibrante simples $/ P /(/ P / \rightarrow O)$ em sílabas CCV.

Os primeiros fonemas selecionados para serem trabalhados foram as fricativas que eram substituí- 
das pelas plosivas [t] e [d], utilizando o mesmo critério de escolha já referido na descrição do sujeito III. A aquisição do traço [+contínuo] delimita as obstruintes fricativas das plosivas, ampliando o sistema fonológico alvo.

Nas atividades de aliteração e rima, o paciente conseguiu produzir adequadamente o fonema $/ \mathrm{s} /$ apenas de forma isolada, apresentando dificuldade na produção do /z/, recorrendo à plosivação. Em relação aos fonemas $/ \Sigma /$ e $/ Z /$, o paciente conseguiu produzi-los sem o auxílio da terapeuta durante a nomeação das palavras. Assim, observou-se mais facilidade com as fricativas palatais $/ \Sigma /$ e $/ Z /$, em que o traço [+ contínuo] foi inserido primeiramente ao sistema fonológico.

Nas sessões de síntese e segmentação silábica e de manipulação e transposição silábica o paciente apresentou a mesma dificuldade anterior em relação à produção da fricativa alveolar sonora /z/ e a inserção do fonema /s/ nas palavras.

Observou-se que o paciente mostrava-se desmotivado devido ao estímulo positivo dado em casa somente a sua irmã, em decorrência da sua melhora no tratamento fonoaudiológico. Desse modo, foi realizada conversa com a família a respeito da importância do reforço positivo que deve ser fornecido em casa pelos familiares.

Nas atividades de identificação fonêmica, o paciente ainda continuava com dificuldade de produção do fonema /z/ e de inserção do fonema /s/ nas palavras.

Ao retornar às atividades de segmentação e síntese silábica, o paciente apresentou evolução significativa, conseguindo produzir os fonemas /s/ e /z/ sem realizar plosivação, tanto isoladamente quanto inseridos nas palavras-alvo. Nesse momento foi observada a superação dos processos fonológicos de plosivação e frontalização de velares, pela aquisição dos traços [+contínuo] e [dorsal] respectivamente ao sistema fonológico.

Foram realizadas, ainda, atividades de manipulação e transposição silábica com a líquida vibrante simples /R/ em sílaba simples CV, e também em $\mathrm{CCV}$, conseguindo produzir adequadamente a vibrante simples nos dois tipos de sílabas, necessitando do apoio de pistas auditivas da estagiária em poucos momentos durante a produção dos encontros consonantais, por ser uma sílaba mais complexa e de aquisição final no processo fonológico.

\section{Desempenho dos sujeitos nas atividades de consciência fonológica.}

Durante a aplicação das atividades de aliteração e rima foi observado que os sujeitos I e II, apesar da dificuldade inicial apresentada, e apenas ao final das duas sessões, conseguiram compreender e realizar adequadamente os objetivos da atividade. Já nos sujeitos III e IV observouse dificuldade na compreensão das regras da atividade, não associando as palavras que continham sons semelhantes, tanto no início quanto no final da palavra. É válido ressaltar que a terapia inicialmente era em dupla e os pacientes expressaram competitividade, entrando em atrito durante toda a sessão. Em decorrência disso, passaram a ser atendidos individualmente na continuidade da aplicação do programa.

Nas atividades de segmentação e síntese silábica, todos os sujeitos apresentaram um desempenho satisfatório nas atividades, conseguindo realizar a síntese e a segmentação das palavras sem nenhuma dificuldade.

Nas tarefas de manipulação e transposição silábica, todos os sujeitos demonstraram dificuldade inicial, porém todos conseguiram superá-las no decorrer das sessões do programa de estimulação da consciência fonológica. No que se refere às atividades de identificação fonêmica, a pesquisadora enfatizou a função distintiva e seqüenciada dos fonemas nas palavras. Os participantes não conseguiram identificar a presença dos fonemas nas palavras. Apenas o sujeito II referiu espontaneamente algumas palavras que continham o fonema em questão, apresentando maior facilidade com os fonemas fricativos.

Após as atividades com identificação fonêmica foi aplicada a atividade 1 de segmentação e síntese fonêmica, para a qual todos os pacientes apresentaram muita dificuldade, não conseguindo realizar a segmentação e a síntese fonêmica de nenhuma das palavras. Diante disso, as pesquisadoras decidiram interromper as atividades de consciência fonêmica e retornar para as habilidades de consciência silábica.

Foram realizadas mais duas sessões com atividades de segmentação e síntese silábica, nas quais os sujeitos apresentaram desempenho satisfatório com maior número de acertos, mostrando-se mais seguros e atentos às solicitações exigidas pelas atividades.

Em seguida, o programa foi realizado com duas sessões de atividades de manipulação e transposição silábica, e os pacientes conseguiram referir adequadamente a maioria das palavras. No entanto, todos eles apresentaram dificuldade nas atividades de subtração e adição silábica quando eram realizadas com a sílaba inicial da palavra. 


\begin{tabular}{|c|c|}
\hline $1^{a}$ e $2^{a}$ sessões & $\begin{array}{l}\text { Aliteração: a criança inicialmente julga dentre três palavras } \\
\text { quais as que iniciem com o mesmo som e posteriormente, a } \\
\text { criança será solicitada a realizar aliterações. } \\
\text { Rima: a criança julga, inicialmente, quais palavras terminam } \\
\text { com o mesmo som, sendo, em seguida, encorajada a formar } \\
\text { rimas. }\end{array}$ \\
\hline $3^{a}$ e $4^{a}$ sessões & $\begin{array}{l}\text { Sintese silábica: a criança é solicitada a unir silabas faladas } \\
\text { pelo pesquisador e informar qual a palavra formada. } \\
\text { Segmentação silábica : a criança irá separar as síla bas de } \\
\text { uma palavra falada pelo pesquisador. }\end{array}$ \\
\hline $5^{a}$ e $6^{a}$ sessões & $\begin{array}{l}\text { Manipulação silábica: a criança irá adicionar e subtrair silabas } \\
\text { das palavras e dizer qual a nova palavra. } \\
\text { Transposição silábica : a criança é solicitada a realizar a } \\
\text { inversão das sílabas, informando qual a nova palavra. }\end{array}$ \\
\hline $7^{a}$ e $8^{a}$ sessões & $\begin{array}{l}\text { Identidade Fonêmica: a criança irá perceber que as palavras } \\
\text { são formadas por estruturas ainda menores que as silabas, } \\
\text { realizando atividades que promovam a percepção desses sons. }\end{array}$ \\
\hline $9^{a}$ e $10^{a}$ sessões & $\begin{array}{l}\text { Sintese fonêmica : a criança une os fonemas falados pelo } \\
\text { pesquisador e diz a palavra formada. } \\
\text { Segmentação fonêmica : a criança irá separar as palavras } \\
\text { faladas pelo pesquisador em fonemas correspondentes. }\end{array}$ \\
\hline \multirow[t]{2}{*}{$11^{\mathrm{a}}$ e $12^{\mathrm{a}}$ sessões } & $\begin{array}{l}\text { Manipulação fonêmica: a criança acrescenta e subtrai } \\
\text { fonemas e refere qual a nova palavra. }\end{array}$ \\
\hline & $\begin{array}{l}\text { Transposição fonêmica: a criança irá inverter os fonemas das } \\
\text { palavras e referir qual a nova palavra. }\end{array}$ \\
\hline
\end{tabular}

Figura 1 - Programa de estratégias

\begin{tabular}{c|l}
\hline FONEMAS & PALAVRAS \\
\hline$/$ s/ & $\begin{array}{l}\text { sapo, sapato, sopa, sala, sacola, saci, moça, } \\
\text { bolsa, laço, etc. }\end{array}$ \\
\hline Iz/ & $\begin{array}{l}\text { Casa, casaco, mes a, mesada, zuada, zebra, } \\
\text { Zeca, José, doze, etc. }\end{array}$ \\
\hline$/ \Sigma /$ & $\begin{array}{l}\text { chave, chinelo, chuva, chão, chá, xícara, } \\
\text { Chica, cacho, caixa, faixa, etc. }\end{array}$ \\
\hline IZ/ & $\begin{array}{l}\text { jaca, jacaré, caju, Juca, janela, Jane, cajá, } \\
\text { girafa, canjica, etc. }\end{array}$ \\
\hline /P / & $\begin{array}{l}\text { barata, areia, arara, pare, cadeira, careta, } \\
\text { praia, cruz, braço, trança, dragão, frio, etc. }\end{array}$ \\
\hline
\end{tabular}

Figura 2 - Palavras utilizadas 


\begin{tabular}{l|l}
\hline 1. Pistas táteis-cinestésicas & $\begin{array}{l}\text { Utilizar a mão do paciente para } \\
\text { perceber o traço de sonoridade na } \\
\text { laringe, e o fluxo aéreo contínuo pela } \\
\text { boca em fonemas fricativos. }\end{array}$ \\
\hline 2. Pistas visuais & $\begin{array}{l}\text { Realizar o modelo da produção do } \\
\text { fonema em frente ao espelho, } \\
\text { mostrando o ponto articulatório } \\
\text { adequado. }\end{array}$ \\
\hline 3. Pistas auditivas & $\begin{array}{l}\text { Utilizar fone de ouvido e microfone para } \\
\text { intensificar a saliência perceptual dos } \\
\text { traços dos fonemas }\end{array}$ \\
\hline
\end{tabular}

Figura 3 - Pistas fonéticas fornecidas

Sujeito I

\begin{tabular}{|l|l|}
\hline ALI & $\mid 3 /$ \\
RIMA & $\mid z /$ \\
\hline SEG sil & $\mid 3 /$ \\
SIN sil & $\mid z /$ \\
\hline MAN sil & $\mid 3 /$ \\
TRAN sil & $\mid z /$ \\
\hline ID fon & $\mid 3 /$ \\
& $\mid z /$ \\
\hline SEG sil & $\mid 3 /$ \\
SIN sil & $\mid z /$ \\
& $\mid 2 /$ \\
\hline MAN sil & $\mid 3 /$ \\
TRAN sil & $\mid z /$ \\
& $\mid 2 /$ \\
\hline
\end{tabular}

Sujeito II

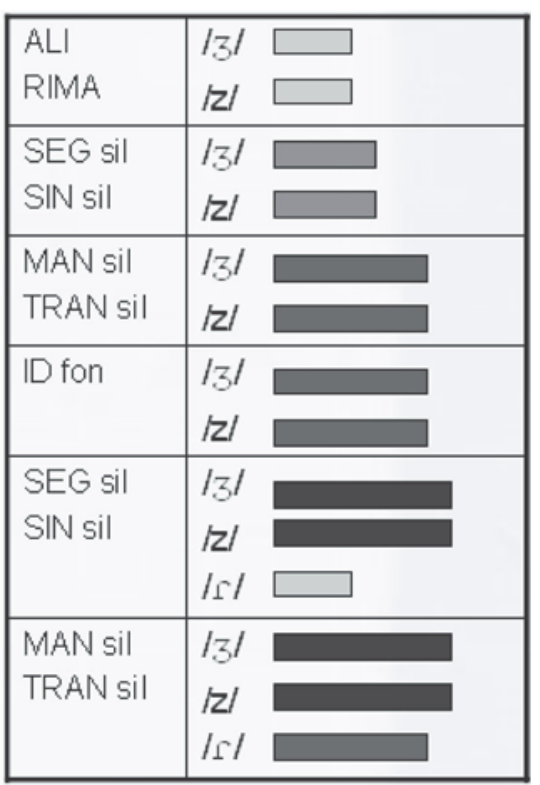

Sujeito III

\begin{tabular}{|c|c|c|}
\hline $\begin{array}{l}\text { ALI } \\
\text { RIMA }\end{array}$ & $\begin{array}{l}|z / \in| S \mid \\
\mid z / \text { e } / \mathrm{s} \mid\end{array}$ & $\begin{array}{l} \\
\square\end{array}$ \\
\hline $\begin{array}{l}\text { SEG sil } \\
\text { SIN sil }\end{array}$ & $\begin{array}{l}|z / e| S \mid \\
|z / \in| s \mid\end{array}$ & \\
\hline $\begin{array}{l}\text { MAN sil } \\
\text { TRAN sil }\end{array}$ & $\begin{array}{l}\mid z / \text { e } / S 1 \\
\mid z / \text { e } / \mathrm{s} \mid\end{array}$ & \\
\hline ID fon & $\begin{array}{l}|z| \text { e } / S \mid \\
|z| \text { e }|s|\end{array}$ & \\
\hline $\begin{array}{l}\text { SEG sil } \\
\text { SIN sil }\end{array}$ & $\begin{array}{l}\mid z / \text { e } / S \mid \\
\mid z / \text { e } / \mathrm{s} / \\
\mid \mathrm{I} /\end{array}$ & \\
\hline $\begin{array}{l}\text { MAN sil } \\
\text { TRAN sil }\end{array}$ & $\begin{array}{l}\mid z / \text { e } / S I \\
\mid z / \text { e } / \mathrm{s} / \\
|\mathrm{I}|\end{array}$ & \\
\hline
\end{tabular}

Sujeito IV

\begin{tabular}{|c|c|c|}
\hline $\begin{array}{l}\text { ALI } \\
\text { RIMA }\end{array}$ & $\begin{array}{l}|z| \text { e }|S| \\
|z| \\
|s|\end{array}$ & $\begin{array}{l}\square \\
\square \\
\square\end{array}$ \\
\hline $\begin{array}{l}\text { SEG sil } \\
\text { SIN sil }\end{array}$ & $\begin{array}{l}|z| \text { e }|S| \\
|z| \\
|s|\end{array}$ & $\begin{array}{l}\square \\
\square \\
\square\end{array}$ \\
\hline $\begin{array}{l}\text { MAN sil } \\
\text { TRAN sil }\end{array}$ & $\begin{array}{l}|z| \text { e } / S \mid \\
|\mathrm{z}| \\
|\mathrm{s}|\end{array}$ & $\begin{array}{l}\square \\
\square \\
\square\end{array}$ \\
\hline ID fon & $\begin{array}{l}|z| \\
|s|\end{array}$ & $\square$ \\
\hline $\begin{array}{l}\text { SEG sil } \\
\text { SIN sil }\end{array}$ & $\begin{array}{l}|z| \\
|s|\end{array}$ & \\
\hline $\begin{array}{l}\text { MAN sil } \\
\text { TRAN sil }\end{array}$ & $\begin{array}{l}|z| \\
|\mathrm{s}|\end{array}$ & \\
\hline
\end{tabular}

Legenda

$\square$ Nã̃o consegue produzir o fonema

$\square$ Produz o fonema isolado

$\square$ Produz com pistas

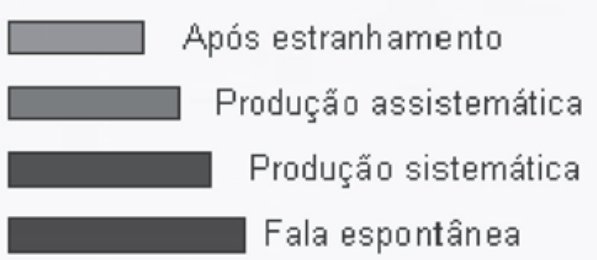

ALI: Aliteração; SEG: Segmentação; SIN: Síntese SIL: Silábica; MAN: Manipulação; TRAN: Transposição

Figura 4 - Quadro ilustrativo da evolução do sistema fonológico dos participantes durante a aplicação das atividades de consciência fonológica 


\section{DISCUSSÃO}

Todas as crianças deste estudo mostraram, inicialmente, desempenho insatisfatório nas atividades de aliteração e rima, apresentando dificuldade em identificar a diferença e semelhança dos fonemas presentes nas palavras. Esse resultado pode ser explicado pelo fato de que as palavras utilizadas nas atividades continham os fonemas que estavam comprometidos no sistema fonológico da criança.

Estudos demonstraram que as crianças com 4 anos apresentam uma habilidade maior em relação às atividades de aliteração e rima do que as crianças na faixa etária dos 6 anos. Isso se deve provavelmente ao abandono das brincadeiras e atividades que envolvem rimas e aliterações ou pelo interesse nos demais sons das palavras, procurando não enfatizar apenas os sons iniciais ou finais ${ }^{17}$.

Durante as atividades de segmentação e síntese silábica, todos os participantes mostraram também dificuldade inicial, porém, após o entendimento das regras, conseguiram um desempenho com mais acertos.

O desempenho satisfatório dos participantes nessas atividades ocorreu porque as atividades de segmentação sonora apresentam-se mais concretas, trazendo pouca ou nenhuma dificuldade para a maioria das crianças na faixa etária de 4 a 6 anos ${ }^{9,18}$.

Nas atividades de identificação, segmentação e síntese fonêmica, as crianças apresentaram um desempenho insatisfatório em compreender o conceito de fonema, não conseguindo identificá-los dentro da palavra. Durante as atividades de segmentação e síntese fonêmica, nenhum dos participantes conseguiu acertos, demonstrando um rendimento bastante insatisfatório.

Sendo assim, decidiu-se por retomar as atividades de consciência silábica, pois, as crianças em questão não estavam aptas para compreender as questões fonêmicas.

É possível que isso tenha ocorrido por dois motivos distintos: o primeiro seria o equívoco das pesquisadoras ao julgar que as crianças estavam aptas para prosseguir no programa. Em estudos futuros, seria interessante realizar sondagens ou avaliações de controle após a aplicação de cada habilidade para analisar se a criança já apresenta condições de passar para a habilidade posterior. Esse processo iria economizar tempo e possibilitar que cada criança evolua no seu próprio ritmo.

O segundo motivo seria que a consciência silábica não representa condição suficiente para consciência fonêmica, e esta última seria adquirida à medida que o processo de alfabetização fosse iniciado.

De fato, estudos comprovam que crianças pequenas têm muito mais facilidade em lidar com atividades que envolvam sílabas, aliterações e rimas do que fonemas, pois a consciência de segmentos suprafonêmicos desenvolve-se espontaneamente ${ }^{15}$.

A consciência fonêmica requer experiências específicas além da simples exposição de conceitos ${ }^{15}$.
A criança necessita de um treino sobre regras de escrita alfabética para conseguir eficiência em identificar fonemas individuais, isto é, necessita do ensino formal e sistemático da correspondência entre os elementos fonêmicos da fala e os elementos grafêmicos da escrita ${ }^{19}$.

As crianças participantes da pesquisa estudam em escola pública municipal que muitas vezes precisa adaptar os conteúdos exigidos no ensino formal, atendendo às características sócio-econômicas e culturais da clientela, predominante de famílias com pouca ou nenhuma instrução e conferindo experiência escassa com relação ao letramento emergente.

Dessa forma, essas crianças podem ser mais lentas no processo de alfabetização, podendo isso estar relacionado com a dificuldade apresentada nas atividades de consciência fonêmica.

Ao retornar para as atividades de segmentação e síntese silábica, os sujeitos I, II, III e IV apresentaram um aproveitamento satisfatório, emitindo as palavras trabalhadas corretamente.

Nas atividades de manipulação e transposição silábica todos os sujeitos mostraram, inicialmente, dificuldade em realizar manipulações na sílaba inicial da palavra, mas conseguiram superá-la satisfatoriamente.

A interrupção do programa formulado para esse estudo no nível de consciência fonêmica e o retorno de sessões reservadas para as habilidades silábicas foi essencial, pois essas habilidades precisavam ser estimuladas o suficiente para iniciar as atividades de consciência fonológica seguintes.

Após o retorno para as habilidades de consciência silábica já trabalhadas, foi observado um desempenho muito melhor, comparado ao inicial, em todos os sujeitos participantes da pesquisa.

A consciência fonológica não é uma variável única, binária, dicotômica. Na realidade, esta habilidade possui uma estrutura hierárquica, atuando por meio de etapas, iniciando com a consciência de unidades mais globais até chegar à consciência dos segmentos fonêmicos da fala ${ }^{20}$.

No decorrer da aplicação do programa foi observado que a evolução do sistema fonológico dos sujeitos I, Il e III está intimamente relacionada com a melhora do desempenho deles nas atividades de consciência fonológica. Ou seja, à medida que eles melhoravam o desempenho nas habilidades de consciência fonológica, havia também a aquisição de novos fonemas em seus sistemas fonológicos.

Apenas o sujeito IV apresentou uma diferença com relação aos outros; apesar do desempenho favorável nas atividades de consciência fonológica, mostrou dificuldade inicial na aquisição dos traços distintivos comprometidos, conseguindo superá-la apenas no final do programa, quando foram repetidas as atividades de consciência silábica. Esse fato pode ser explicado por dois pressupostos. O primeiro seria a desmotivação mostrada 
pelo paciente no início da aplicação do programa, em que ele, em muitos momentos, não realizava o que era solicitado pela terapeuta.

A motivação apresentada pela criança durante o processo terapêutico irá influenciar diretamente na evolução do sistema fonológico, facilitando a automatização para a fala espontânea ${ }^{6}$.

O segundo pressuposto seria que a evolução tardia referente ao sistema fonológico apresentada pelo paciente estaria relacionada com o retorno para as atividades de consciência silábica, as quais promoveram uma melhor percepção dos traços anteriormente ausentes na fala da criança.

A evolução da terapia fonoaudiológica nos casos de desvio fonológico depende da utilização de um modelo teórico abrangente de fonologia para planejar o tratamento. E em relação à percepção da criança sobre o som produzido, ela deve monitorar suas respostas e para isso precisa ter uma consciência fonológica, que seria a percepção dos menores constituintes da palavra ${ }^{3}$.

No processo terapêutico dos sujeitos I e ll o trabalho foi iniciado com o traço [+voz] nos fonemas fricativos, pois a sua duração consegue expor a sonoridade e a criança passa a perceber a presença do traço. $\mathrm{O}$ trabaIho realizado com fonemas contendo o traço [+contínuo] (IZI, IZ/) possibilitou a generalização do traço [+voz] em fonemas com o traço [-contínuo], as plosivas $/ \mathrm{g} / / / \mathrm{d} /$ e/b/, e do traço [+ contínuo] na classe de líquidas com a aquisição da vibrante simples /P/. Para os sujeitos III e IV, foram estimuladas as fricativas, em que o traço [+contínuo] foi trabalhado e adquirido por ambos os sujeitos e, além disso, o sujeito III conseguiu a aquisição do traço [dorsal] sem que este fosse estimulado, caracterizando, novamente, o processo de generalização. Observou-se que a estimulação de um traço hierarquicamente mais complexo possibilitou a aquisição de traços menos complexos e a generalização do próprio traço para outros fonemas não trabalhados especificamente no programa. Esse processo de generalização é um critério essencial para avaliar a eficácia da abordagem terapêutica, ou seja, quanto maior for a quantidade de fonemas generalizados pela criança, maior é a eficiência do processo terapêutico ${ }^{21}$.

A estimulação de traços mais complexos, que estão em níveis mais elevados na hierarquia, pode promover a aquisição de sons menos complexos, promovendo assim o processo de generalização de traços não trabalhados ${ }^{2}$.

Ao término do estudo, a análise dos dados da reavaliação mostraram que todos os sujeitos conseguiram uma evolução bastante significativa, eliminando praticamente todos os processos fonológicos e adquirindo todos os traços comprometidos. Os quatro sujeitos da pesquisa receberam alta fonoaudiológica permanente.

As alterações de fala das crianças com desvio fonológico podem estar relacionadas com uma deficiência na sua capacidade de perceber que a fala pode ser segmentada e manipulada em seus segmentos. Ou seja, pacientes com alterações fonológicas podem ter um desempenho ineficiente nas habilidades de consciência fonológica ${ }^{22}$. Sendo assim, uma terapia baseada em atividades que promovam o desenvolvimento da consciência fonológica podem propiciar a evolução do sistema fonológico.

\section{CONCLUSÃO}

Devido à evolução apresentada por todos os sujeitos estudados, conclui-se que a melhora nas habilidades de consciência fonológica parece favorecer também o desenvolvimento do sistema fonológico, pois permite que a criança fique mais atenta em relação aos sons da fala e perceba a importância da presença dos traços que se encontram comprometidos na sua fala.

O processo terapêutico em casos de desvio fonológico baseado na hierarquia dos traços distintivos facilita o processo de generalização de traços comprometidos, acelerando assim a evolução terapêutica.

\section{ABSTRACT}

Purpose: to check the development of the adult-target phonological system in public school children, aged between 05 to 08 years with phonological deviation. Methods: the active phonological processes were identified by digitally recording the audio in spontaneous speech samples, naming pictures, and mimicking words that make up a specific phonological test (ABFW). An activity program was employed to foster phonological awareness skills and the theoretical ground for the ranking of distinctive features. Results: following the end of the program, the entire group of patients showed significant progress, having overcome all the existing phonological processes and acquired the features that were not present. The patients' phonological system broadened as their performance in phonological awareness activities improved. Conclusion: the phonetic approach to phonological deviation, when based on the ranking of distinctive features and on phonological awareness, favored the overcoming of phonological processes and the significant development of the patients' phonological system.

KEYWORDS: Speech Therapy; Phonetics; Speech; Language 


\section{REFERÊNCIAS}

1.Wertzner HF. O distúrbio fonológico em crianças falantes do português: descrição e medidas de severidade [livre docência]. São Paulo (SP): Faculdade de Medicina da Universidade de São Paulo; 2002.

2. Mota HB. Aquisição segmental do português: um modelo implicacional de complexidade de traços [doutorado]. Porto Alegre (RS): Pontifícia Universidade Católica do Rio Grande do Sul; 1996.

3.Lamprecht RR. Os processos nos desvios fonológicos evolutivos. Estudo sobre quatro crianças [mestrado]. Porto Alegre (RS): Pontifícia Universidade Católica do Rio Grande do Sul; 1986.

4. Matzenauer CLB. Bases para o entendimento da aquisição fonológica. In: Lampretch RR. Aquisição fonológica do português - perfil de desenvolvimento e subsídios para terapia. PortoAlegre: Artmed; 2004. p. 33-58.

5. Mota HB. Fonologia: intervenção. In: Ferreira LP, Befi-lopes DM, Lomongi SCO. Tratado de fonoaudiologia. São Paulo: Roca; 2004. p. 787-814.

6. Mota HB. Aquisição segmental do português: um modelo implicacional de complexidade de traços. Letras de Hoje 1997; 32: 23-47.

7.Mota HB, Pereira LF. A generalização na terapia dos desvios fonológicos: experiência com duas crianças. Pró-fono. 2001; 13: 141-6.

8.Freitas GCM. Sobre a Consciência fonológica. In: Lampretch RR. Aquisição fonológica do português perfil de desenvolvimento e subsídios para terapia. Porto Alegre: Artmed; 2004. p. 179-92.

9.Paes CTS. Pessoa ACRG. Habilidades fonológicas em crianças não alfabetizadas e alfabetizadas. Rev CEFAC 2005; 7 (2): 149-57.

10. Lundberg I, Frost J, Petersen O. Effects of an extensive program for stimulating phonological awareness in preschool children learning. Res $Q$. 1988; 23: 262-84.

11. Burgess SR, Lonigan CJ. Bidirectional relations of phonological sensitivity and prereading abilities: evidence from a preschool sample. J Exp Child
Psychol. 1998; 70(2): 117-41.

12. Santos MTM, Navas ALGP, Pereira LD. Estimulando a consciência fonológica. In: Pereira L, Schochat E. Processamento auditivo central: manual de avaliação. São Paulo: Lovise; 1997.

13. Andrade CRF, Befi-lopes DM, Fernades FDM, Wertzner HF. ABFW: teste de linguagem infantil nas áreas de fonologia, vocabulário, fluência e pragmática. São Paulo: Pró-Fono; 2004.

14. IPA - International Phonetic Alphabet; 1993. Documento on-line. Disponível em: URL: http:// scripts.sil.org/cms/scripts/ page.php?site_id=nrsi\&item_id=encore-ipa-download. Acesso em 22 de fev. 2007.

15. Capovilla AGS. Leitura, escrita e consciência fonológica desenvolvimento, intercorrelações e interações [doutorado]. São Paulo (SP). Universidade de São Paulo; 1999.

16. Bandini HHM. Um programa para a promoção de consciência fonológica em pré-escolares aplicado em sala de aula [mestrado]. São Carlos (SP). Universidade Federal de São Carlos; 2003.

17. Andrezza-Balestrin C, Cielo CA. O professor préescolar e sua prática em consciência fonológica. Rev Soc Bras Fonoaudiol. 2003; 8: 27-33.

18. Maluf MR, Barrera SD. Consciência fonológica e linguagem escrita em pré-escolares. Psicol Reflex Crít. 1997; 10: 125-45.

19. Bradley L, Bryante PE. Categorizing sounds and learning to read - a causual conection. Nature 1983; 301: 419-21.

20. Jekins R, Bowen L. Facilitating development of preliterate children's phonological abilities. Top Lang Disord 1994; 2: 26-39.

21. Barberena LS, Keske-soares M, Mota HB. Generalização no tratamento com o /R/ em um caso de desvio fonológico médio-moderado. Rev Soc Bras Fonoaudiol. 2004; 9: 229-36.

22. Morales MV, Mota HB, Keske-soares M. Consciência fonológica: desempenho de crianças com e sem desvios fonológicos evolutivos. Pró-fono 2002; 14: 153-64.

RECEBIDO EM: 22/08/2006

ACEITO EM: 28/05/2007

Endereço para correspondência:

Rua Clementino Dumont, $n^{\circ} 317$, ap. 203

Maceió - AL

CEP: $57055-190$

Tel: (82) 32419328

E-mail: rafaspindola@hotmail.com 